Fellows have lent apparatus from their own departments for particular projects. The response to this scheme has been very encouraging and consideration is now being given to placing under the ægis of the Committee the research projects at present assisted by Shell Research, Ltd. The Committee looks forward both to receiving further requests from schools and to the continued valuable support of Fellows of the Royal Society and others in acting as advisers and assisting in the extension of its activities.

\section{Nuclear Reactors on a Commercial Basis}

IN reply to a question in the House of Commons on February 5, the Prime Minister stated that the United Kingdom Euratom Agreement was signed on February 4 and the text was published as a White Paper. The prospects for sales of British reactors in the Euratom market, he said, will depend on commercial considerations; but the established achievements of the Calder Hall prototypes and the developments incorporated in the later commercial designs now available for export should give British manufacturers a good prospect of success in Euratom countries. Mr. Macmillan agreed that the ability of the United States to supply fuel for the first year free of charge made it difficult to compete in contracts for power stations, although he believes that Britain is further advanced in this field than the United States are. It is, however, an expanding field and besides the Euratom Agreement Britain has already made separate agreements with individual countries, and this has resulted in an arrangement for a British plant to be erected in Italy.

\section{Fog Dispersal}

THE Parliamentary Secretary to the Ministry of Transport and Civil Aviation stated in reply to a question in the House of Commons on February 4 that research carried out by the Ministry of Supply indicates that the most promising method of fog dispersal is the thermal one known as F.I.D.O. His Ministry is collaborating with the Ministry of Supply in tests with a new type of F.I.D.O. installed at an R.A.F. aerodrome. This is a high-pressure system with a new type of burner which, it is hoped, will be more economical in operation. The old system was very expensive both to install and to operate. Although F.I.D.O. could provide a clear area, there would still remain the problem of the wall of fog which the aircraft would have to penetrate first. It is considered unlikely that automatic landing equipment would provide a complete solution to the problem.

\section{Electrical Instrument Test Service}

The British Scientific Instrument Research Association has established an electrical instrument test service at its laboratories in Chislehurst, Kent. Although originally set up at the request of members of the Association, the service is now available to other firms and organizations. It is operated under the supervision of the National Physical Laboratory and will test and issue certificates for instruments up to 'Precision Grade' accuracy. Calibration of d.c. meters between $\mathrm{I} \mathrm{mV}$. and $500 \mathrm{~V}$. and between $2 \mu \mathrm{amp}$. and $2 \mathrm{amp}$. can be undertaken immediately. In the near future the latter range is to be extended to 25 amp., and the calibration of a.c. instruments over the ranges $1-500 \mathrm{~V}$. and $10 \mathrm{~m}$.amp. $-25 \mathrm{amp}$. will be undertaken. Charges for the service will be appreciably less than the cost of National Physical
Laboratory certification. Further information can be obtained from the Director of Research, British Scientific Instrument Research Association, South Hill, Chislehurst, Kent.

\section{Bird Migration}

IN addition to its established quarterly journal, Bird Study, the British Trust for Ornithology has launched a half-yearly publication entitled Bird Migration (1, No. 1; December 1958. iv $+40 \mathrm{pp}$. $2 s$. 6d.). This is related to the Trust's recently adopted scheme for co-ordinating the activities of the score of bird observatories which now form a remarkable network around the British coasts, and for ensuring the complete availability and summary publication of the data collected. A grant made for five years by the Nuffield Foundation has enabled the Trust to appoint a whole-time migration research officer, Mr. Kenneth Williamson, who edits the new journal. This first issue includes a series of summary reports from the individual observatories on the autumn migration of 1958 , followed by an editorial review of the more notable aspects of the movements as a whole. The season is shown to have been an interesting one in several respects, and this convenient account of it-accompanied by weather maps where necessary-is welcome. The value over a sequence of years should be cumulative.

\section{Plastics Abstracts}

Plastics Investigations is publishing a new weekly journal, Plastics Abstracts, which aims to give a comprehensive abstracting service covering British patent specifications and periodical articles dealing with the science, technology and applications of plastics. A valuable feature of these abstracts is the promptness with which they are published-normally one week after publication of the original patent specifications, and within two weeks of publication of the periodical articles. The preparation of this journal is based on a complete weekly scrutiny of British patent specifications and the regular examination of about 250 periodicals. Detailed author, patent and subject indexes will be published annually, and subscribers' requests for specific information contained in the current year's abstracts will be answered free of charge. Plastics Abstracts is obtainable from the publishers, Plastics Investigations, 23 Canonsfield Road, Welwyn, Hertfordshire. The subscription rates are $£ 25$ annually including postage, or $£ 35$ by air-mail ; single copies can be obtained for 10s., or 14s. by air-mail.

\section{Drilling a Borehole to the Earth's Mantle}

Prof. Hans Pettersson has recently written an article in the Stockholms-Tidningen about drilling a deep hole to the Mohorovičić discontinuity between the Earth's mantle and the surface rocks, in which he refers to the article by Dr. T. F. Gaskell in Nature of September 13, p. 692, which discussed this project. Prof. Pettersson reminds his readers that the only knowledge of the depth of the base of the Earth's crustal rocks is that obtained from the study of earthquakes. These observations, however, do not allow one to say with certainty what is the rock material which constitutes the Earth's mantle. It is possible that some of the research concerned with the planets and the Moon may give useful clues to what material exists inside the Earth, but there is a strong argument for spending part of the limited amount of money available for research on the more 